\title{
Weight Trajectories from Birth and Bone Mineralization at 7 Years of Age
}

\author{
Teresa Monjardino, MPH ${ }^{1,2}$, Teresa Rodrigues, MD, PhD ${ }^{1,2,3}$, Hazel Inskip, MSc, PhD, FFPH ${ }^{4}$, \\ Nicholas Harvey, MA, MB, BChir, PhD, FRCP ${ }^{4}$, Cyrus Cooper, OBE, DL, FMedSci ${ }^{4}$, Ana Cristina Santos, MPH, PhD ${ }^{1,2}$, and \\ Raquel Lucas, MSc, $\mathrm{PhD}^{1,2}$
}

\begin{abstract}
Objective To assess whether different trajectories of weight gain since birth influence bone mineral content (BMC) and areal bone mineral density (aBMD) at 7 years of age.

Study design We studied a subsample of 1889 children from the Generation XXI birth cohort who underwent whole-body dual-energy radiograph absorptiometry. Weight trajectories identified through normal mixture modeling for model-based clustering and labeled "normal weight gain," "weight gain during infancy," "weight gain during childhood," and "persistent weight gain" were used. Differences in subtotal BMC, aBMD, and size-corrected BMC (scBMC) at age 7 years according to weight trajectories were estimated through analysis of covariance.

Results Compared with the "normal weight gain" trajectory, children in the remaining trajectories had significantly greater BMC, aBMD, and scBMC at age 7 years, with the strongest associations for "persistent weight gain" (girls [BMC: 674.0 vs $559.8 \mathrm{~g}$, aBMD: 0.677 vs $0.588 \mathrm{~g} / \mathrm{cm}^{2}$, scBMC: 640.7 vs $577.4 \mathrm{~g}$ ], boys [BMC: 689.4 vs 580.8 g, aBMD: 0.682 vs $0.611 \mathrm{~g} / \mathrm{cm}^{2}$, scBMC: 633.0 vs $\left.595.6 \mathrm{~g}\right]$ ). After adjustment for current weight, and alternatively for fat and lean mass, children with a "weight gain during childhood" trajectory had greater BMC and aBMD than those with a "normal weight gain" trajectory, although significant differences were restricted to girls (BMC: 601.4 vs $589.2 \mathrm{~g}$, aBMD: 0.618 vs $0.609 \mathrm{~g} / \mathrm{cm}^{2}$ ).
\end{abstract}

Conclusion Overall, children following a trajectory of persistent weight gain since birth had clearly increased bone mass at 7 years, but weight gain seemed slightly more beneficial when it occurred later rather than on a normal trajectory during the first 7 years of life. ( $J$ Pediatr 2017; 191:117-24).

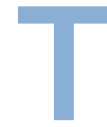

he theoretical approach currently used to model peak adult bone mass and subsequent fracture risk builds on the premise that there is important tracking of this characteristic throughout the life course, modulated by geneenvironment interactions. ${ }^{1}$ Empirically, there is also growing evidence of early life influences on bone accrual. ${ }^{2,3}$

The anthropometric phenotype comprises a set of partially modifiable influences on bone strength from as early as intrauterine life. ${ }^{3-5}$ Strong cross-sectional relations between body size and bone mass and density have been established clearly in children, reflecting, to a large extent, the adaptation of skeletal modeling to loading. ${ }^{6-9}$ More recently, sensitive periods for the effect of height and weight on children's bone mass and geometry have been found, ${ }^{10-12}$ suggesting that qualitative differences in the timing of growth may have relevant quantitative impact on bone accrual. However, it is not clear whether differences in the overall shape of growth since birth, particularly weight trajectories, also have differential impact on bone mineral mass and density. Indeed, increased overall exposure to weight during growth, in dose and/or duration, may positively influence bone health as a consequence of greater and/or longer exposure to loading, especially from the lean component. ${ }^{13}$ Among the statistical approaches to examine the role of growth trajectories in later health and disease, group-based modeling methods seek to identify distinctive subgroups of individuals that follow similar growth patterns. ${ }^{14,15}$

\footnotetext{
aBMD Areal bone mineral density

BMC Bone mineral content

BMI Body mass index

DXA Dual-energy radiograph absorptiometry

scBMC Size-corrected bone mineral content
}

From the ${ }^{1}$ Instituto de Saúde Pública, Universidade do Porto (Epidemiology Research Unit [EPIUnit], Institute of Public Health of the University of Porto); ${ }^{2}$ Department of Public Health, Forensic Sciences and Medical Education, Faculdade de Medicina, Universidade do Porto (University of Porto Medical School); ${ }^{3}$ Department of Gynecology and Obstetrics, S. João Hospital Center, Porto, Portugal; and ${ }^{4}$ Medical Research Council (MRC) Lifecourse Epidemiology Unit, University of Southampton, Southampton General Hospital, Southampton, United Kingdom

Generation XXI was funded by European Regional Development Fund (FEDER) through the Operational Programme Competitiveness and Internationalization and national funding from the Foundation for Science and Technology (FCT) - Portuguese Ministry of Science, Technology and Higher Education (POCl-01-0145FEDER-016838 and POCI-01-0145-FEDER-016837), under the projects "BioAdversity: Como a adversidade social na infância condiciona a saúde: A biologia da adversidade social" (Ref. FCT PTDC/DTP-EPI/1687/ 2014) and "PathMOB.: Risco cardiometabólico na infância: desde o início da vida ao fim da infância" (Ref. FCT PTDC/DTP-EPI/3306/2014); by the Unidade de Investigação em Epidemiologia - Instituto de Saúde Pública da Universidade do Porto (EPIUnit) (POCl-010145-FEDER-006862; Ref. UID/DTP/04750/2013); and by Administração Regional de Saúde Norte (Regional

Department of Ministry of Health) and Fundação Calouste Gulbenkian; PhD Grant SFRH/BD/92370/2013 (T.M.) and the Postdoc grant SFRH/BPD/88729/2012 (R.L.), cofunded by the FCT and the Human Potential Operating Programme of the European Social Fund (POPH/FSE Program); and the FCT Investigator contract IF/01060/ 2015 (A.C.S.). This study is also a result of the project DOCnet (NORTE-01-0145-FEDER-000003), supported by Norte Portugal Regional Operational Programme (NORTE 2020), under the PORTUGAL 2020 Partnership Agreement, through the European Regional Development Fund (ERDF). The authors declare no conflicts of interest.

Portions of this study were presented as an oral presentation during the European Congress of Epidemiology in Munich, Germany, August 28-September 2, 2016, and at the XXXIV Reunión Científica de la SEE, XI Congresso da Associação Portuguesa de

Epidemiologia in Seville, Spain, September 14-16, 2016 and published in abstract form.

0022-3476/\$ - see front matter. @ 2017 Elsevier Inc. All rights reserved.

https://doi.org10.1016/j.jpeds.2017.08.033 
So far, few studies have explored the relationship between growth and bone and research has focused on age-delimited periods, rather than capturing the overall shape of weight gain. ${ }^{10-12,16-19}$

The aim of this study was to estimate the influence of distinct weight trajectories since birth on bone mineral content (BMC) and areal bone mineral density (aBMD) at 7 years of age. Specifically, we aimed to assess whether those trajectories have explanatory power for bone mass at age 7 years in addition to concurrent anthropometrics.

\section{Material and Methods}

This work was embedded in the Generation XXI study, a prospective population-based birth cohort established in Porto, Portugal. ${ }^{20,21}$ To summarize, recruitment took place between April 2005 and August 2006 at all level III public units providing obstetric and neonatal care that covered the metropolitan area of Porto. Of the invited mothers, 8495 agreed to participate (91.4\%), and a total of 8647 infants (gestational age $\geq 24$ weeks) were enrolled. At 4 years of age (April 2009 to July 2011), 7459 children were reevaluated $(86.3 \%$ of the initial cohort). Again, at 7 years of age (April 2012 to April 2014), 6889 children were reassessed (79.7\% of the initial cohort).

The Generation XXI study protocol conforms to the ethical principles outlined in the 1964 Declaration of Helsinki and was approved by the Ethics Committee of Hospital de São João and the University of Porto Medical School and by the
Portuguese Data Protection Authority. Written informed consent from parents (or legal substitute) and oral assent from children were obtained at each evaluation.

In the follow-up evaluation at 7 years of age, children assessed between December 1, 2012, and August 31, 2013, were invited to undergo a whole-body dual-energy radiograph absorptiometry (DXA) scan. From the 5225 children with a weight trajectory assignment, DXA scanning was performed successfully in 1889 children (48.3\% girls), who comprised our final sample for analysis (Figure 1). Following standard manufacturer protocols, total body BMC $(\mathrm{g})$, bone area $\left(\mathrm{cm}^{2}\right)$, and aBMD $\left(\mathrm{g} / \mathrm{cm}^{2}\right)$ were obtained while children were barefoot in light clothing and without metal accessories with a Hologic Discovery QDR 4500W device (Hologic Inc, Bedford, Massachusetts), software version 13.3.0.1. To ensure that the lines between adjacent subregions of the body were placed correctly, scans were examined twice, directly after the scanning procedure and at a later time point by a second, well-trained research assistant. We performed daily quality assurance tests using a spine phantom. As recommended by the International Society for Clinical Densitometry for research in pediatric populations, total body less head (subtotal) measures were used. ${ }^{22}$ Size-corrected bone mineral content (scBMC) was derived separately for girls and boys by linear regression of BMC on bone area and addition of the residuals of the regression to the mean sample BMC. ${ }^{23}$

Birth weights were abstracted from clinical records. At ages 4 and 7 years, anthropometric measurements were

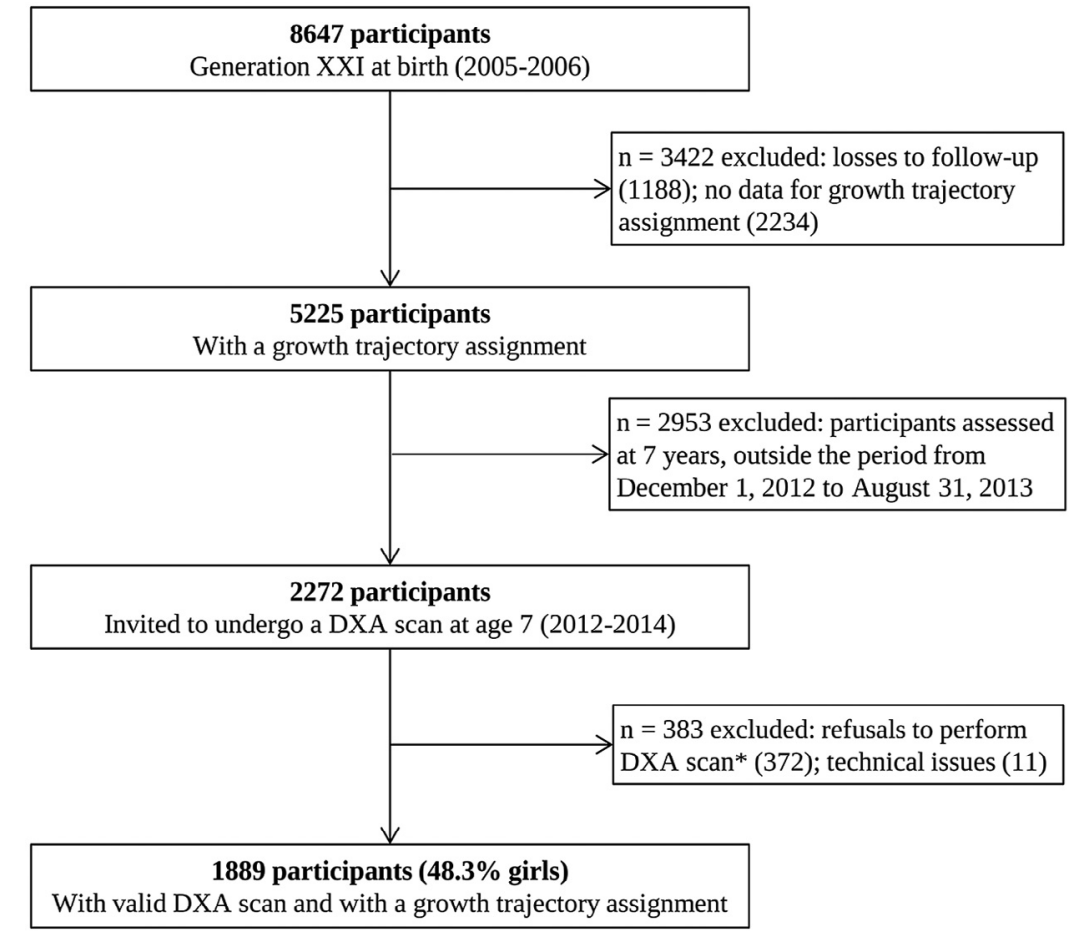

Figure 1. Flowchart of the participants included for analysis from the Generation XXI cohort, Porto, Portugal. *Participants who refused to participate in the DXA evaluation $(n=171)+$ participants who scheduled 3 different appointments but did not show up for evaluation or did not respond to our invitation after at least 5 attempts $(n=201)$. 


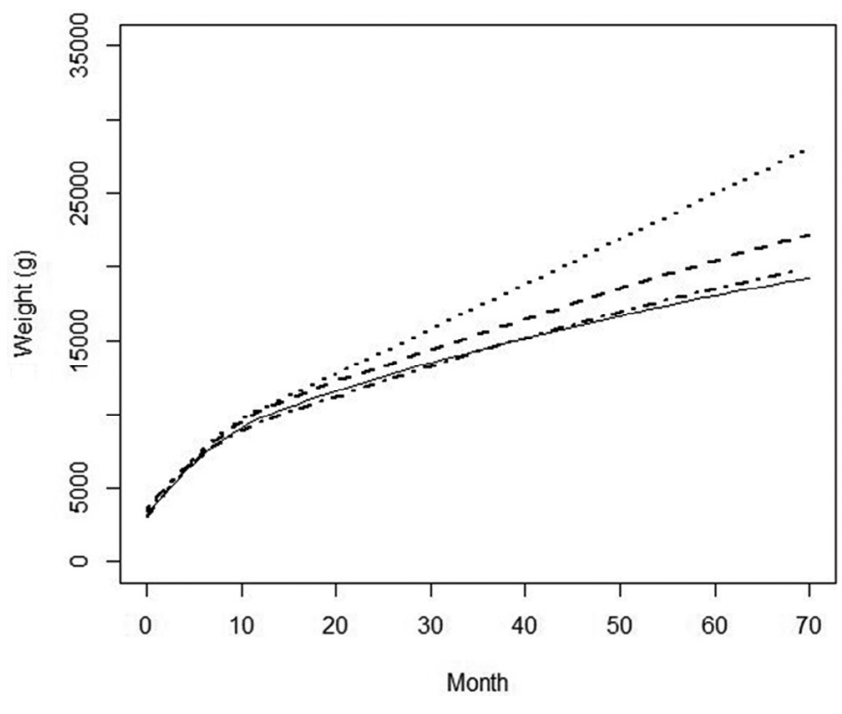

Figure 2. Weight trajectories in the Generation XXI cohort. Solid line, "normal weight gain" trajectory; dashed-dotted line, "weight gain during infancy" trajectory; dashed line, "weight gain during childhood" trajectory; dotted line, "persistent weight gain" trajectory.

performed by trained examiners according to standard procedures. Weight was measured with a digital scale to the nearest $0.1 \mathrm{~kg}$, and height was measured with a wall stadiometer to the nearest $0.1 \mathrm{~cm}$ while the child was barefoot and in light clothing. Body mass index (BMI) $\left(\mathrm{kg} / \mathrm{m}^{2}\right)$ was calculated. At age 7 years, fat mass $(\mathrm{kg})$ and lean mass $(\mathrm{kg})$ were obtained during DXA scanning described for bone assessment. Patterns in weight gain trajectories were identified through normal mixture modeling for model-based clustering in 5225 participants, as previously described. ${ }^{24}$ Four different weight trajectories for both sexes combined were defined, which are plotted in Figure 2. The 4 trajectories were labeled "normal weight gain," "weight gain during infancy," "weight gain during childhood," and "persistent weight gain." The "normal weight gain" denomination was chosen because the average weight in this trajectory closely overlapped the 50th weight-for-age percentile curve according to the World Health Organization Child Growth Standards..$^{25,26}$

To address potential confounding, we selected variables that are plausible common causes of weight trajectories and BMC or $\mathrm{aBMD}$ and are not likely to mediate their relation. These included gestational age, maternal background characteristics (age at child birth, prepregnancy BMI, and smoking during pregnancy), and socioeconomic position (measured through maternal educational level at child birth). Data on confounders were self-reported complemented with information retrieved from medical records.

\section{Statistical Analyses}

We used 2 approaches to model the effects of weight on childhood bone mineralization: examining individual associations of weight at specific ages and assessing the role of weight trajectories. First, we computed multiple linear regression of bone BMC, aBMD, and scBMC at 7 years on weight at birth, at 4 and at 7 years of age to estimate regression coefficients, and respective $95 \%$ CI. Sex-specific z scores were computed for each DXA-derived bone parameter based on the sexspecific means and SDs derived from the study sample. Ageand sex-specific weight $\mathrm{z}$ scores were computed according to the World Health Organization. ${ }^{25}$ Separate models were fitted for girls and boys. In the second approach, differences in BMC, $\mathrm{aBMD}$, and scBMC according to weight trajectories were estimated through ANCOVA, and adjusted means are presented.

To test the direct effect of trajectories on bone mass not mediated by current body size, adjusted models including height and weight (or fat and lean mass) at 7 years, for BMC and $\mathrm{BBMD}$, or weight (or fat and lean mass), for scBMC, were computed. Post-hoc pairwise comparisons of crude and adjusted means between trajectories were performed with the Tukey-Kramer correction for multiple comparisons. Sensitivity analyses to assess regional effects were carried out by restricting the outcomes to weight-bearing and nonweight-bearing anatomical sites (lower and upper limbs, respectively). Because of growth profile specificities, additional sensitivity analyses were carried out by excluding, consecutively, children born very preterm (gestational age $<32$ weeks, $\mathrm{n}=11$ ) and all children born preterm ( $<37$ weeks, $\mathrm{n}=122$ ). Statistical analysis was performed with Stata, version 11.2, for Windows (Stata Corp LP, College Station, Texas).

\section{Results}

Regarding maternal and child characteristics, we observed small differences between participants included in this analysis and all the remaining participants of the cohort (Table I; available at www.jpeds.com). In crude analysis, weight at all ages was associated positively with all DXA-derived bone parameters at age 7 years (Table II). Overall, the magnitude of effect estimates increased with advancing age. After adjustment for height at 7 years, cross-sectional positive associations of weight with $\mathrm{BMC}$ and $\mathrm{aBMD}$ remained but were strongly attenuated in girls (BMC: standardized $\beta=0.41,95 \%$ CI 0.36-0.46; aBMD: $\beta=0.55$, 95\% CI 0.51-0.58) and boys (BMC: $\beta=0.28,95 \%$ CI $0.24-$ 0.32; aBMD: $\beta=0.46,95 \%$ CI 0.42-0.51). After adjustments for current weight and height, the effect of weight at age 4 years on $\mathrm{BMC}$ and $\mathrm{aBMD}$ at 7 years also was attenuated strongly but remained positive and statistically significant. Similarly, after adjustment for current weight, birth weight was weakly or not associated with BMC and aBMD. For scBMC, after adjustment for the later weight measure, the direction of the associations with weight at birth and at age 4 reversed (Table II).

In crude analysis, both girls and boys following a "persistent weight gain" trajectory presented the greatest BMC (girls: $674.0 \mathrm{~g}$, boys: $689.4 \mathrm{~g}$ ) and aBMD means (girls: $0.677 \mathrm{~g} / \mathrm{cm}^{2}$, boys: $0.682 \mathrm{~g} / \mathrm{cm}^{2}$ ) followed by children in the "weight gain during childhood" trajectory (BMC [girls: 627.4 g, boys: $646.6 \mathrm{~g}$ ] and aBMD [girls: $0.635 \mathrm{~g} / \mathrm{cm}^{2}$, boys: $0.655 \mathrm{~g} / \mathrm{cm}^{2}$ ]), then those in the "weight gain during infancy" trajectory (BMC [girls: $605.5 \mathrm{~g}$, boys: $631.2 \mathrm{~g}$ ] and aBMD [girls: $0.621 \mathrm{~g} / \mathrm{cm}^{2}$, boys: $\left.0.638 \mathrm{~g} / \mathrm{cm}^{2}\right]$ ), and lastly by children with a "normal weight gain" 
Table II. Associations between weight (at birth, at 4 and at 7 years of age) and BMC, aBMD, and scBMC at 7 years

\begin{tabular}{|c|c|c|c|c|c|c|c|c|}
\hline & \multicolumn{4}{|c|}{ Girls } & \multicolumn{4}{|c|}{ Boys } \\
\hline & $\mathbf{n}$ & $\begin{array}{c}\text { BMC z score } \\
\beta(95 \% \text { CI) }\end{array}$ & $\begin{array}{c}\text { aBMD z score } \\
\beta(95 \% \mathrm{Cl})\end{array}$ & $\begin{array}{c}\text { scBMC z score } \\
\beta(95 \% \text { CI) }\end{array}$ & $\mathbf{n}$ & $\begin{array}{c}\text { BMC z score } \\
\beta(95 \% \text { CI) }\end{array}$ & $\begin{array}{c}\text { aBMD z score } \\
\beta \text { (95\% CI) }\end{array}$ & $\begin{array}{c}\text { scBMC z score } \\
\beta(95 \% \mathrm{CI})\end{array}$ \\
\hline Birth weight z score & 912 & & & & 977 & & & \\
\hline Model 1 & & $0.21(0.16-0.27)$ & $0.19(0.13-0.25)$ & $0.08(0.03-0.14)$ & & $0.13(0.08-0.19)$ & $0.12(0.07-0.18)$ & $0.04(-0.02,0.10)$ \\
\hline Model 2 & & $0.06(0.02-0.09)$ & $0.05(0.01-0.09)$ & $-^{*}$ & & $-0.00(-0.04,0.03)$ & $0.00(-0.04,0.05)$ & $-^{*}$ \\
\hline Model 3 & & $0.03(-0.00,0.06)$ & $0.01(-0.02,0.04)$ & $-0.06(-0.10,-0.02)$ & & $-0.00(-0.04,0.03)$ & $0.00(-0.03,0.03)$ & $-0.03(-0.08,0.01)$ \\
\hline Weight at 4 y z score & 906 & & & & 965 & & & \\
\hline Model 1 & & $0.68(0.64-0.72)$ & $0.72(0.69-0.76)$ & $0.54(0.49-0.59)$ & & $0.70(0.66-0.75)$ & $0.71(0.66-0.75)$ & $0.40(0.34-0.46)$ \\
\hline Model 2 & & $0.31(0.26-0.35)$ & $0.47(0.42-0.52)$ & $-^{*}$ & & $0.30(0.25-0.35)$ & $0.43(0.37-0.48)$ & $-^{*}$ \\
\hline Model 3 & & $0.08(0.02-0.14)$ & $0.09(0.03-0.14)$ & $-0.06(-0.15,0.01)$ & & $0.12(0.06-0.18)$ & $0.08(0.02-0.14)$ & $-0.20(-0.29,-0.12)$ \\
\hline Weight at 7 y $z$ score & 912 & & & & 977 & & & \\
\hline Model 1 & & $0.66(0.62-0.70)$ & $0.74(0.70-0.77)$ & $0.60(0.56-0.64)$ & & $0.61(0.57-0.65)$ & $0.66(0.62-0.69)$ & $0.45(0.40-0.50)$ \\
\hline Model 2 & & $0.41(0.36-0.46)$ & $0.55(0.51-0.58)$ & $-^{*}$ & & $0.28(0.24-0.32)$ & $0.46(0.42-0.51)$ & 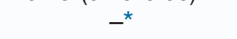 \\
\hline
\end{tabular}

$\beta$, regression coefficient.

The values presented are regression coefficients (SD change in bone outcome per SD change in weight) and $95 \% \mathrm{Cl}$.

Model 1 represents the crude analysis.

Model 2 is adjusted for height at $7 \mathrm{y}$ of age; * ${ }^{2} \mathrm{BMC}$ models were not adjusted for height because height and bone area are extremely correlated.

Model 3 is similar to Model 2 but additionally adjusted for weight at $7 \mathrm{y}$ of age.

trajectory (BMC [girls: $559.8 \mathrm{~g}$, boys: $580.8 \mathrm{~g}$ ] and aBMD [girls: $0.588 \mathrm{~g} / \mathrm{cm}^{2}$, boys: $0.611 \mathrm{~g} / \mathrm{cm}^{2}$ ]) (Figure 3). Compared with the "normal weight gain" group, bone parameters were significantly greater in all the remaining trajectories. Between participants in trajectories "weight gain during infancy" and "weight gain during childhood," differences in BMC and aBMD were small and nonsignificant. Regarding scBMC, boys assigned to "normal weight gain" and "weight gain during infancy" did not differ in scBMC (595.6 vs $599.8 \mathrm{~g}, P>.05$ ).

Adjustment of the linear regression coefficients for maternal age, prepregnancy BMI, smoking during pregnancy, socioeconomic position, and gestational age did not change the results appreciably (data not shown). However, after adjustment for height and weight at 7 years of age, associations between weight trajectory and DXA-derived bone parameters were attenuated, and most lost significance. Girls in the "weight gain during childhood" trajectory had the greatest adjusted BMC, which was significantly greater than the estimate for the "normal weight gain" trajectory ( 601.4 vs $589.2 \mathrm{~g}, P<.05$ ). Also for aBMD, girls with "weight gain during childhood" had the greatest adjusted mean, significantly greater than that in the "normal weight gain" group ( 0.618 vs $\left.0.609 \mathrm{~g} / \mathrm{cm}^{2}, P<.05\right)$. In boys, increased adjusted mean $\mathrm{BMC}$ and $\mathrm{aBMD}$ in the "weight gain during childhood" trajectory also was observable, even though differences by trajectories were not statistically significant. For scBMC, the "persistent weight gain" group of girls had significantly greater adjusted mean in comparison with the "normal weight gain" group ( 600.4 vs $589.8 \mathrm{~g}, P<.05)$. Boys with a trajectory of "weight gain during infancy" had significantly lower adjusted mean scBMC in comparison with the "normal weight gain” group (593.2 vs $602.1 \mathrm{~g}, P<.05$ ) (Figure 3 ).

Adjustment for fat and lean mass at 7 years of age, instead of weight, did not change appreciably the associations between weight trajectories and DXA-derived bone parameters. Despite that, lean mass at 7 years was associated more strongly with $\mathrm{BMC}$ and aBMD than fat mass. This finding was reversed for scBMC, which was associated more strongly with fat than lean mass (Table III; available at www.jpeds.com).

\section{Sensitivity Analysis}

We computed the associations between weight trajectories and bone physical properties at the upper limbs and lower limbs, representing nonweight-bearing and weight-bearing skeletal sites, respectively, and the results of those associations were similar to those found for total body minus head parameters (Table IV; available at www.jpeds.com). Also, after excluding children born very preterm $(n=11)$ and all preterm $(n=122)$ consecutively, associations between weight trajectories and bone parameters remained similar to those found for the whole sample of children.

\section{Discussion}

Using data from a large population-based prospective cohort, we found that children who followed a persistent weight gain trajectory had clearly increased bone mass and density at 7 years of age. When differences in concurrent body size were taken into account, later weight gain predicted slightly greater BMC and aBMD than normal weight gain.

Over the conventional approach of studying weight measurements at specific age-delimited periods, longitudinal analysis using mixture modeling has the advantage of classifying overall shapes of growth, whose qualitative differences may have quantitative impact on the outcome assessed..$^{14,15,27}$ The application of trajectory-based models to better understand the etiology and developmental course of health outcomes has grown, but most attention has been devoted to the prediction of cardiometabolic outcomes. ${ }^{26,28-33}$ To the best of our knowledge, this is the first study modeling the effect of overall weight trajectories in relation to bone mineralization.

In both sexes, for crude associations, we found a clear gradient whereby children who remained in a persistent weight gain trajectory had greater bone mass, followed by those who kept intermediate weight trajectories (weight gain during infancy or childhood), and finally by those in a normal weight gain trajectory. This finding is consistent with the observed associations between weight at each age and bone mass and 


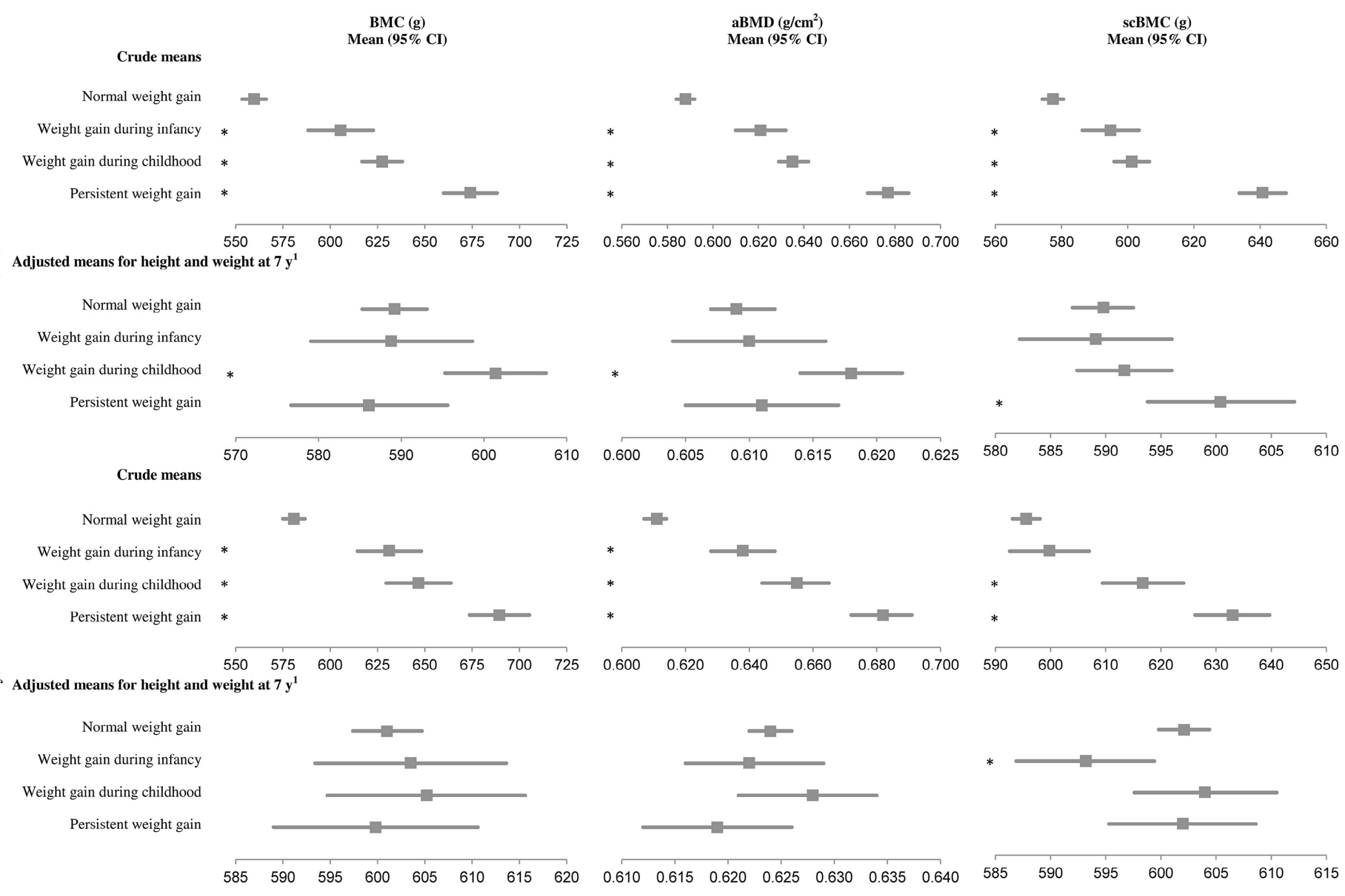

Figure 3. Crude and adjusted means of BMC, aBMD, and scBMC at 7 years of age, according to weight trajectories, and stratified by sex. ${ }^{1} \mathrm{scBMC}$ means adjusted for weight at 7 years. Asterisks indicate statistically significant differences compared with "normal weight gain" trajectory. 
density at 7 years reflecting that long-lasting exposure to loading — both gravitational and muscle loading — is likely osteogenic due to the cumulative effect of enhanced mechanical strain, both in dose and duration. Our results regarding crude associations between weight trajectories and DXAderived bone parameters were remarkably similar between boys and girls, reinforcing previous evidence that the pediatric skeleton responds positively to increased body weight. ${ }^{34-36}$ Specifically, previous studies have shown strong effects of the mechanical stimulation of body weight on BMC and aBMD from early life and in both sexes. ${ }^{19,37,38}$

In addition to the total effect of trajectories, we attempted to estimate the direct effect of weight trajectories on BMC and aBMD independent of current body weight. Our finding that those associations were attenuated largely after current weight adjustment is consistent with a strong biological and statistical dependence between the trajectory itself and the final weight attained. If current weight is understood as the result of cumulative growth up to that point (ie, a proxy for the overall trajectory), it becomes both conceptually and technically challenging to disentangle the 2 contributions, and any estimation of the effect of the trajectory is, to a large extent, mediated by current weight. ${ }^{39}$ In addition, we cannot exclude the possibility that adjustment for current size may have induced collider bias, particularly when trajectory-bone associations changed qualitatively after adjustment. ${ }^{39,40}$ Collider bias refers to the spurious association created between the exposure (weight trajectory) and the outcome (DXA-derived bone parameter), in the model adjusted for the potential mediator (current body size), when there are mediator-outcome confounders, ${ }^{41,42}$ such as unmeasured chronic conditions.

Nevertheless, for a comprehensive interpretation of trajectory-outcome associations, we have presented, as recommended, models with and without adjustment for later size (Figure 3). ${ }^{39}$ We found relevant differences in the weightadjusted bone measures that should be highlighted: whereas scBMC remained significantly greater among girls in a trajectory of "persistent weight gain," we found that children in a trajectory of "weight gain during childhood" had greater BMC and $\mathrm{aBMD}$ than the normal weight gain group, after current weight adjustment. We hypothesize that girls and boys in a trajectory of "weight gain during childhood" may represent a group of children with a different metabolic profile that might be of particular significance, as seen in our previous observation with regard to blood pressure. ${ }^{26}$

With respect to the relative contribution of each component of weight, our results suggest, like previous works, that lean mass is a more important determinant of childhood bone mineralization than fat mass. ${ }^{13}$ Indeed lean mass may be a closer surrogate of both types of mechanical forces acting on the skeleton, muscle, and gravitational, whereas fat mass reflects more directly the influence of gravity. ${ }^{43}$ This stronger association with lean mass was not observable, however, for scBMC, which possibly represents a distinct dimension from BMC and aBMD.

Previous studies on growth and bone in children have quantified independent effect estimates during age-delimited periods of growth. In the Southampton Women's Survey, using con- ditional models of change, heterogeneous effects were observed: growth in the first 2 years of life was associated more strongly with 4- and 6-year-old bone mass and geometry than growth at later ages. ${ }^{10,11}$ In the Generation R study, likewise through conditional growth modeling, growth in height and weight during the first year of life had stronger associations with BMC and BMD at age 6 years than later anthropometrics. ${ }^{12}$ Another study in adolescents found, however, that early growth was less associated with bone mass than growth later in childhood. ${ }^{16}$ Comparisons between these results and ours are hampered by different methodologic approaches: previous research aimed to identify critical periods of growth for bone development, and we intended to assess the effect of overall growth shapes on bone status. ${ }^{14}$

Nevertheless, the results of this study should be interpreted taking into account specific limitations and methodologic options. Bone parameters were assessed by DXA which, despite being well validated and the most commonly used technique to assess bone density in children, ${ }^{22}$ does not provide a measure of true volumetric density. ${ }^{13}$ Additional limitations of DXA include the systematic overestimation of BMD as bone size increases and the partial artefactual increase of aBMD with weight, due to effect of fat on radiograph absorption. Also, only a single measurement of BMC and aBMD was acquired. Second, the analytical approach used to define weight trajectories shares the limitations of other clustering techniques. These include some degree of subjectivity, given that the process of extracting the number of groups/trajectories is guided by researchers' decisions, in addition to statistical fit. Because the assignment of individuals to trajectories is based on the highest estimated probability of group membership, latent trajectories should not be interpreted as literally distinct entities but as an approximation to a more complex reality. ${ }^{15}$

This study is strengthened by the use of data from a large, prospective, population-based birth cohort with remarkably abundant childhood anthropometric records, which provides greater statistical power than in most previous studies. In addition, by using data from children born during a short period of time, we have minimized the probability of confounding by age or birth cohort effects. Also, the differences in maternal and child characteristics between participants included and excluded were minor in terms of magnitude and should not limit the generalizability of the findings to the overall cohort. In addition, our analysis was conducted with 3 different bone measurements. Even though all measures are 2-dimensional, scBMC is considered an adequate measure of BMC corrected for skeletal size differences and an approximate measure of volumetric BMD. ${ }^{44-46}$

In this population-based cohort, children following a trajectory of persistent weight gain since birth had clearly increased DXA-derived bone parameters at 7 years of age. Current weight was an accurate proxy of the overall trajectory from birth in terms of its association with bone mass but weight gain seemed slightly more beneficial when it occurred later rather than in an average normal trajectory during the first 7 years of life. This study supports that overall weight trajectory shapes the development of BMC and $\mathrm{aBMD}$, suggesting that changes 
to that trajectory, either natural or induced, may modulate bone accrual in childhood.

We gratefully acknowledge the families enrolled in Generation XXI, all members of the research team, and the participating hospitals and their staff. We also thank Professor Milton Severo (EPIUnit - Instituto de Saúde Pública, Universidade do Porto, Porto, Portugal) for support with statistical analyses, and Dr Luísa Nogueira (Department of Radiology, School of Health Technology of Porto/Polytechnic Institute of Porto, Porto, Portugal) for providing the technical conditions necessary for whole-body DXA scans.

Submitted for publication Apr 26, 2017; last revision received Jul 3, 2017; accepted Aug 15, 2017

Reprint requests: Teresa Monjardino, MPH, EPIUnit - Instituto de Saúde Pública, Universidade do Porto, Rua das Taipas 135, 4050-600 Porto,

Portugal. E-mail: teresa.monjardino@ ispup.up.pt

\section{References}

1. Heaney RP, Abrams S, Dawson-Hughes B, Looker A, Marcus R, Matkovic V, et al. Peak bone mass. Osteoporos Int 2000;11:985-1009.

2. Cooper C, Westlake S, Harvey N, Javaid K, Dennison E, Hanson M. Review: developmental origins of osteoporotic fracture. Osteoporos Int 2006;17:33747.

3. Javaid MK, Cooper C. Prenatal and childhood influences on osteoporosis. Best Pract Res Clin Endocrinol Metab 2002;16:349-67.

4. Bachrach LK. Acquisition of optimal bone mass in childhood and adolescence. Trends Endocrinol Metab 2001;12:22-8.

5. Harvey N, Dennison E, Cooper C. Osteoporosis: a lifecourse approach. J Bone Miner Res 2014;29:1917-25.

6. Pietrobelli A, Faith MS, Wang J, Brambilla P, Chiumello G, Heymsfield SB. Association of lean tissue and fat mass with bone mineral content in children and adolescents. Obes Res 2002;10:56-60

7. Schoenau E, Fricke O. Mechanical influences on bone development in children. Eur J Endocrinol 2008;159(suppl 1):S27-31.

8. Mikkola TM, Sipila S, Rantanen T, Sievanen H, Suominen H, Kaprio J, et al. Genetic and environmental influence on structural strength of weightbearing and non-weight-bearing bone: a twin study. J Bone Miner Res 2008;23:492-8.

9. Timpson NJ, Sayers A, Davey-Smith G, Tobias JH. How does body fat influence bone mass in childhood? A Mendelian randomization approach. J Bone Miner Res 2009;24:522-33.

10. Harvey NC, Mahon PA, Kim M, Cole ZA, Robinson SM, Javaid K, et al. Intrauterine growth and postnatal skeletal development: findings from the Southampton Women's Survey. Paediatr Perinat Epidemiol 2012;26:3444.

11. Harvey NC, Cole ZA, Crozier SR, Ntani G, Mahon PA, Robinson SM, et al. Fetal and infant growth predict hip geometry at 6 y old: findings from the Southampton Women's Survey. Pediatr Res 2013;74:450-6.

12. Heppe DH, Medina-Gomez C, de Jongste JC, Raat H, Steegers EA, Hofman A, et al. Fetal and childhood growth patterns associated with bone mass in school-age children: the Generation R Study. J Bone Miner Res 2014;29:2584-93

13. Moon RJ, Cole ZA, Crozier SR, Curtis EM, Davies JH, Gregson CL, et al. Longitudinal changes in lean mass predict pQCT measures of tibial geometry and mineralisation at 6-7 years. Bone 2015;75:10510.

14. Tu YK, Tilling K, Sterne JA, Gilthorpe MS. A critical evaluation of statistical approaches to examining the role of growth trajectories in the developmental origins of health and disease. Int J Epidemiol 2013;42:132739.

15. Nagin DS, Odgers CL. Group-based trajectory modeling in clinical research. Annu Rev Clin Psychol 2010;6:109-38.

16. Jensen RB, Vielwerth S, Frystyk J, Veldhuis J, Larsen T, Molgaard C, et al. Fetal growth velocity, size in early life and adolescence, and prediction of bone mass: association to the GH-IGF axis. J Bone Miner Res 2008;23:439-46.

17. Kuh D, Wills AK, Shah I, Prentice A, Hardy R, Adams JE, et al. Growth from birth to adulthood and bone phenotype in early old age: a British birth cohort study. J Bone Miner Res 2014;29:123-33.

18. Weaver CM, Gordon CM, Janz KF, Kalkwarf HJ, Lappe JM, Lewis R, et al. The National Osteoporosis Foundation's position statement on peak bone mass development and lifestyle factors: a systematic review and implementation recommendations. Osteoporos Int 2016;27:1281-386.

19. Ay L, Jaddoe VW, Hofman A, Moll HA, Raat H, Steegers EA, et al. Foetal and postnatal growth and bone mass at 6 months: the Generation R Study. Clin Endocrinol (Oxf) 2010;74:181-90.

20. Larsen PS, Kamper-Jorgensen M, Adamson A, Barros H, Bonde JP, Brescianini S, et al. Pregnancy and birth cohort resources in Europe: a large opportunity for aetiological child health research. Paediatr Perinat Epidemiol 2013;27:393-414.

21. Alves E, Correia S, Barros H, Azevedo A. Prevalence of self-reported cardiovascular risk factors in Portuguese women: a survey after delivery. Int J Public Health 2012;57:837-47.

22. Crabtree NJ, Arabi A, Bachrach LK, Fewtrell M, El-Hajj Fuleihan G, Kecskemethy HH, et al. Dual-energy X-ray absorptiometry interpretation and reporting in children and adolescents: the revised 2013 ISCD Pediatric Official Positions. J Clin Densitom 2014;17:225-42.

23. Tobias JH, Cook DG, Chambers TJ, Dalzell N. A comparison of bone mineral density between Caucasian, Asian and Afro-Caribbean women. Clin Sci 1994;87:587-91.

24. Fonseca MJ, Durão C, Lopes C, Santos AC. Weight following birth and childhood dietary intake: a prospective cohort study. Nutrition 2017;33:5864 .

25. WHO Multicentre Growth Reference Study Group. WHO Child Growth Standards: length/height-for-age, weight-for-age, weight-for-length, weightfor-height and body mass index-for-age: Methods and development. Geneva: World Health Organization; 2006.

26. Pais C, Correia-Costa L, Moura C, Mota C, Severo M, Guerra A, et al. Accelerated growth during childhood is associated with increased arterial stiffness in prepubertal children. Int J Cardiol 2016;204:83-5.

27. Nagin DS. Group-based trajectory modeling: an overview. Ann Nutr Metab 2014;65:205-10.

28. Araujo J, Severo M, Barros H, Mishra GD, Guimaraes JT, Ramos E. Developmental trajectories of adiposity from birth until early adulthood and association with cardiometabolic risk factors. Int J Obes (Lond) 2015;39:1443-9.

29. Ventura AK, Loken E, Birch LL. Developmental trajectories of girls' BMI across childhood and adolescence. Obesity (Silver Spring) 2009;17:206774 .

30. Ziyab AH, Karmaus W, Kurukulaaratchy RJ, Zhang H, Arshad SH. Developmental trajectories of Body Mass Index from infancy to 18 years of age: prenatal determinants and health consequences. J Epidemiol Community Health 2014;68:934-41.

31. Huang RC, de Klerk NH, Smith A, Kendall GE, Landau LI, Mori TA, et al. Lifecourse childhood adiposity trajectories associated with adolescent insulin resistance. Diabetes Care 2011;34:1019-25.

32. Huang RC, Burrows S, Mori TA, Oddy WH, Beilin LJ. Lifecourse adiposity and blood pressure between birth and 17 years old. Am J Hypertens 2015;28:1056-63.

33. Giles LC, Whitrow MJ, Davies MJ, Davies CE, Rumbold AR, Moore VM. Growth trajectories in early childhood, their relationship with antenatal and postnatal factors, and development of obesity by age 9 years: results from an Australian birth cohort study. Int J Obes (Lond) 2015;39:104956.

34. Frost HM. The mechanostat: a proposed pathogenic mechanism of osteoporoses and the bone mass effects of mechanical and nonmechanical agents. Bone Miner 1987;2:73-85.

35. Frost HM. Bone's mechanostat: a 2003 update. Anat Rec A Discov Mol Cell Evol Biol 2003;275:1081-101.

36. Gafni RI, Baron J. Childhood bone mass acquisition and peak bone mass may not be important determinants of bone mass in late adulthood. Pediatrics 2007;119(suppl 2):S131-6. 
37. Videhult FK, Ohlund I, Hernell O, West CE. Body mass but not vitamin $\mathrm{D}$ status is associated with bone mineral content and density in young school children in northern Sweden. Food Nutr Res 2016;60:30045.

38. Behringer M, Gruetzner S, McCourt M, Mester J. Effects of weightbearing activities on bone mineral content and density in children and adolescents: a meta-analysis. J Bone Miner Res 2014;29:467-78.

39. Lucas A, Fewtrell MS, Cole TJ. Fetal origins of adult disease-the hypothesis revisited. BMJ 1999;319:245-9.

40. Schisterman EF, Cole SR, Platt RW. Overadjustment bias and unnecessary adjustment in epidemiologic studies. Epidemiology 2009;20:488-95.

41. Cole SR, Platt RW, Schisterman EF, Chu H, Westreich D, Richardson D, et al. Illustrating bias due to conditioning on a collider. Int J Epidemiol 2010;39:417-20.

42. Richiardi L, Bellocco R, Zugna D. Mediation analysis in epidemiology: methods, interpretation and bias. Int J Epidemiol 2013;42:1511-9.
43. Kohrt WM, Barry DW, Schwartz RS. Muscle forces or gravity: what predominates mechanical loading on bone? Med Sci Sports Exerc 2009;41:2050-5.

44. Prentice A, Parsons TJ, Cole TJ. Uncritical use of bone mineral density in absorptiometry may lead to size-related artifacts in the identification of bone mineral determinants. Am J Clin Nutr 1994;60:83742.

45. Macdonald-Wallis C, Tobias JH, Smith GD, Lawlor DA. Relation of maternal prepregnancy body mass index with offspring bone mass in childhood: is there evidence for an intrauterine effect? Am J Clin Nutr 2010;92:872-80.

46. van den Hooven EH, Heppe DH, Kiefte-de Jong JC, Medina-Gomez C, Moll HA, Hofman A, et al. Infant dietary patterns and bone mass in childhood: the Generation R Study. Osteoporos Int 2015;26:1595604.

50 Years Ago in The Journal of PEDIATRICs

\section{Subacute Sclerosing Panencephalitis}

Blattner RJ. J Pediatr 1967;71:910-3

$\mathrm{R}$ . J. Blattner reviewed the history of the discovery of the clinical condition subacute sclerosing panencephalitis (SSPE) and the new focus on a measles-like virus as causative at the time of his writing. The condition was first described by Dawson in 1933 as "subacute inclusion body encephalitis." The appellation was broadened to "subacute sclerosing leukoencephalitis" by van Bogaert in 1945, and the distinction of diffuse involvement led to the term SSPE. As cases accrued, the typical clinical course was described as inexorable mental deterioration and movement disorder, with a terminal phase of optic atrophy, akinetic mutism, and signs suggestive of decortication.

The findings of intranuclear and intracytoplasmic inclusions in neurons and neuroglia, with perivascular infiltration of lymphocytes and plasma cells, suggested a virus as the likely cause. In 1967, Connolly and coworkers in Belfast, Ireland reported finding high levels of antibody to measles virus in cerebrospinal fluid and serum of 3 patients with SSPE. By the 1970s, the sequence of events leading to SSPE was clear. Following the acquisition of wild measles (rubeola) virus (usually in the first 2 years of life), in rare instances, CNS infection with an altered measles virus became chronic and persistently active, leading to diffuse gray and white matter destruction over years. This writer remembers the almost continuous presence of severely affected patients with SSPE in the clinical research center at the old St Christopher's Hospital for Children, where Angie DiGeorge and Harold Lischner studied therapies such as ventricular instillation of activated lymphocytes in the futile attempt to halt progressive brain tissue destruction.

SSPE disappeared from the US after the universal implementation of live measles vaccine in toddlers. The rare cases of SSPE (such as recently reported in The Journal ${ }^{1}$ ) currently diagnosed in school-aged children living in the United States occur in children who traveled before they were immunized to countries where measles continued/continues to be prevalent. When performed, molecular testing of brain tissue from current cases identifies altered measles virus of clades specific to the country of previous travel where virus was acquired.

We are reminded by this history of SSPE of our vulnerability to the dreaded complications of measles, which are virtually preventable by the rigid application of current recommendations for immunization. These recommendations include 2 doses of measles vaccine for every child after the first birthday to protect the child and limit virus circulation in the community (the herd), and measles vaccine for every infant at least 6 months of age who will travel to any country with ongoing measles activity (ie, any country without a contiguous border with the US).

Sarah S. Long, MD

Department of Pediatrics

St Christopher's Hospital for Children

Philadelphia, Pennsylvania

\section{Reference}

1. Holt RL, Kann D, Rassbach CE, Schwenk HT, Ritter JM, Rota PA, et al. Subacute sclerosing panencephalitis: the foothold in undervaccination. J Pediatr 2016;179:259-62. 


\begin{tabular}{|c|c|c|c|c|}
\hline \multirow[b]{2}{*}{ Characteristics } & \multicolumn{2}{|c|}{ Included } & \multicolumn{2}{|c|}{ Excluded } \\
\hline & $\mathbf{n}$ & Mean (SD) or $\mathrm{n}(\%)$ & $\mathbf{n}$ & Mean (SD) or $n(\%)$ \\
\hline \multicolumn{5}{|l|}{ Mother } \\
\hline Age at delivery, $\mathrm{y}^{*}$ & 1889 & $30.2(5.0)$ & 6752 & $28.6(5.7)$ \\
\hline Prepregnancy $\mathrm{BMI}, \mathrm{kg} / \mathrm{m}^{2}$ * & 1868 & $24.1(4.2)$ & 6480 & $23.8(4.3)$ \\
\hline Educational level $^{\dagger}$ & 1883 & & 6708 & \\
\hline Primary & & $750(39.8)$ & & $3478(51.8)$ \\
\hline Secondary & & $533(28.3)$ & & $1767(26.3)$ \\
\hline Higher & & $600(31.9)$ & & $1463(21.8)$ \\
\hline \multicolumn{5}{|l|}{ Smoking during pregnancy ${ }^{\dagger}$} \\
\hline First trimester & 1872 & $368(19.7)$ & 6656 & $1588(23.9)$ \\
\hline Second trimester & 1869 & $224(12.0)$ & 6650 & $1108(16.7)$ \\
\hline Third trimester & 1869 & $209(11.2)$ & 6645 & $1042(15.7)$ \\
\hline \multicolumn{5}{|l|}{ Child } \\
\hline $\mathrm{Sex}^{\dagger}$ & 1889 & & 6758 & \\
\hline Girls & & $912(48.3)$ & & $3324(49.2)$ \\
\hline Boys & & $977(51.7)$ & & $3434(50.8)$ \\
\hline Gestational age, wk* & 1889 & $38.7(1.6)$ & 6737 & $38.4(2.0)$ \\
\hline Very preterm $(<32 \mathrm{wk})^{\dagger}$ & & $11(0.6)$ & & $112(1.7)$ \\
\hline Moderate/late preterm $(32 \text { to }<37 \mathrm{wk})^{\dagger}$ & & $111(5.9)$ & & $592(8.8)$ \\
\hline Age at the 7-y follow-up evaluation, $\mathrm{mo}^{*}$ & 1889 & $85.1(2.4)$ & 3953 & $85.9(3.1)$ \\
\hline Birth weight, $\mathrm{g}^{*}$ & 1889 & $3194(481)$ & 6757 & $3136(552)$ \\
\hline Birth length, $\mathrm{cm}^{*}$ & 1886 & $49(2)$ & 6688 & $49(3)$ \\
\hline Weight at $4 \mathrm{y}, \mathrm{kg}^{*}$ & 1871 & $17.9(2.8)$ & 4072 & $18.3(3.1)$ \\
\hline Height at $4 \mathrm{y}, \mathrm{cm}^{*}$ & 1871 & $104.9(4.5)$ & 4063 & $105.5(5.3)$ \\
\hline Weight at $7 \mathrm{y}, \mathrm{kg}^{*}$ & 1886 & $25.9(5.0)$ & 3948 & $26.4(5.4)$ \\
\hline Height at $7 \mathrm{y}, \mathrm{cm}^{*}$ & 1886 & $123.4(5.3)$ & 3948 & $123.8(5.4)$ \\
\hline Weight trajectories $^{\dagger}$ & 1889 & & 3336 & \\
\hline Normal weight gain & & $1250(66.2)$ & & $2013(60.3)$ \\
\hline Weight gain during infancy & & $158(8.4)$ & & $351(10.5)$ \\
\hline Weight gain during childhood & & $275(14.6)$ & & $568(17.0)$ \\
\hline Persistent weight gain & & $206(10.9)$ & & $404(12.1)$ \\
\hline
\end{tabular}


Table III. Adjusted means of bone physical properties at 7 years of age, according to weight trajectories, and linear regression coefficients (95\% CI) for the associations between weight trajectories and bone physical properties (adjusted for fat and lean mass)

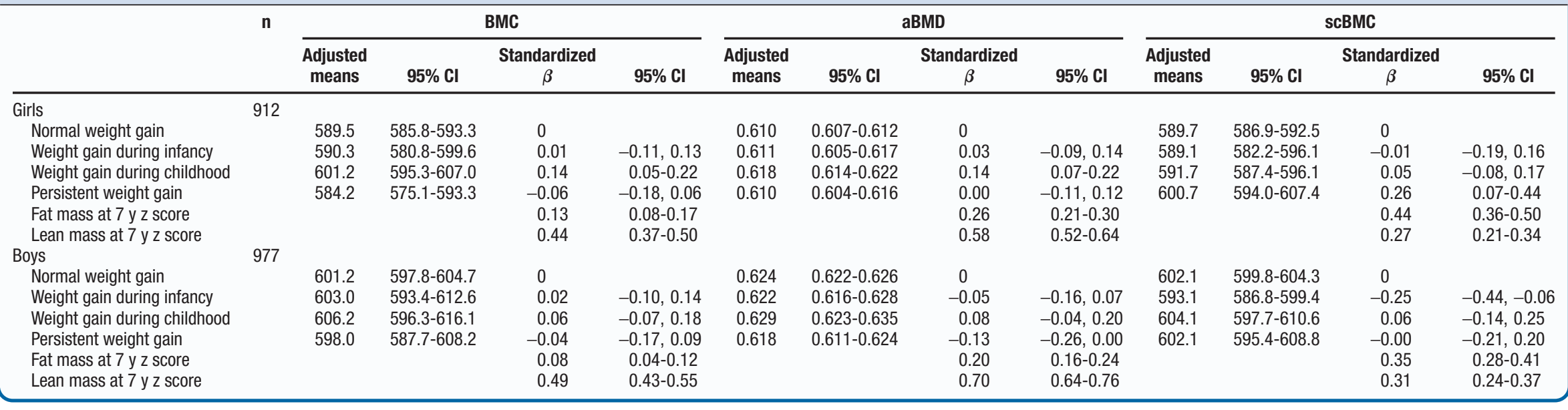

The values presented are regression coefficients (SD change in bone outcome per SD change in fat mass and lean mass) and $95 \%$ Cls. BMC and ABMD models are adjusted for height.

Table IV. Linear regression coefficients $(95 \% \mathrm{CI})$ for the associations between weight trajectories and bone physical properties at 7 years of age, in subtotal, weightbearing, and nonweight-bearing skeletal sites

\begin{tabular}{|c|c|c|c|c|c|c|c|c|c|}
\hline & \multicolumn{3}{|c|}{ BMC z score } & \multicolumn{3}{|c|}{ aBMD z score } & \multicolumn{3}{|c|}{ scBMC z score } \\
\hline & Subtotal & $\begin{array}{c}\text { Nonweight- } \\
\text { bearing skeletal } \\
\text { site (upper limbs) }\end{array}$ & $\begin{array}{l}\text { Weight-bearing } \\
\text { skeletal site } \\
\text { (lower limbs) }\end{array}$ & Subtotal & $\begin{array}{c}\text { Nonweight- } \\
\text { bearing skeletal } \\
\text { site (upper limbs) }\end{array}$ & $\begin{array}{l}\text { Weight-bearing } \\
\text { skeletal site } \\
\text { (lower limbs) }\end{array}$ & Subtotal & $\begin{array}{c}\text { Nonweight- } \\
\text { bearing skeletal } \\
\text { site (upper limbs) }\end{array}$ & $\begin{array}{l}\text { Weight-bearing } \\
\text { skeletal site } \\
\text { (lower limbs) }\end{array}$ \\
\hline Normal weight gain & 0 & 0 & 0 & 0 & 0 & 0 & 0 & 0 & 0 \\
\hline Weight gain during infancy & $0.56(0.41-0.70)$ & $0.54(0.39-0.69)$ & $0.52(0.37-0.67)$ & $0.54(0.39-0.68)$ & $0.56(0.41-0.70)$ & $0.52(0.38-0.67)$ & $0.24(0.09-0.40)$ & $0.47(0.32-0.61)$ & $0.52(0.37-0.67)$ \\
\hline Weight gain during childhood & $0.74(0.63-0.86)$ & $0.71(0.60-0.83)$ & $0.72(0.60-0.83)$ & $0.78(0.67-0.90)$ & $0.73(0.62-0.85)$ & $0.77(0.66-0.88)$ & $0.52(0.40-0.64)$ & $0.64(0.53-0.76)$ & $0.72(0.60-0.83)$ \\
\hline Persistent weight gain & $1.28(1.15-1.41)$ & $1.22(1.09-1.36)$ & $1.22(1.08-1.35)$ & $1.43(1.30-1.56)$ & $1.50(1.38-1.63)$ & $1.45(1.32-1.58)$ & $1.26(1.12-0.39)$ & $1.50(1.37-1.62)$ & $1.22(1.08-1.35)$ \\
\hline
\end{tabular}

